\title{
HILDA HILST LÊ BECKETT
}

\section{Olga Kempinska}

RESUMO: O artigo investiga a importância capital da prosa de Samuel Beckett no processo da elaboração da poética das "ficções" de Hilda Hilst. Tomando como seu ponto de partida os traços intertextuais de Molloy em Fluxo-floema, o trabalho debruça-se sobre a interiorização do palco da comunicação e enfatiza os elementos dramáticos da dicção poética hilstiana, insistindo no dilaceramento da subjetividade sob o efeito da violência inerente à coincidência da palavra e da emoção.

PALAVRAS-CHAVE: Hilda Hilst; Samuel Beckett; intertextualidade

ABSTRACT: The paper investigates the capital importance of Samuel Beckett's prose in the process of the elaboration of Hilda Hilst's "fictions". Taking as its starting point some of the intertextual traces of Molloy in Fluxo-floema, the paper analyzes the interiorization of the communication scene and emphasizes dramatic elements of Hilst's poetics, insisting on the painful splitting of the subjectivity under the effect of the violence inherent to the coincidence of word and emotion.

KEYWORDS: Hilda Hilst; Samuel Beckett; Intertextuality. 
Sobre esse grande real interior onde fantasmas mortos e vivos, natureza e vazio, tudo aquilo que não para e que nunca será, juntam-se em uma única evidência e para um único testemunho. Samuel Beckett, Homenagem a Jack B. Yeats

Enfim, é preciso continuar. Hilda Hilst, Fluxo-floema

A relação intertextual entre Fluxo-floema (1970) e Molloy (1951, em francês, e 1955, em inglês) afirma-se logo na primeira página do livro. Hilda Hilst cita na epígrafe uma passagem do texto beckettiano:

Havia em suma três, não, quatro Molloys.

O das minhas entranhas, a caricatura que eu fazia desse, o de Gaber e o que, em carne e osso, em algum lugar esperava por mim.

Havia outros evidentemente. Mas fiquemos por aqui, se não se importam, no nosso circulozinho de iniciados. ${ }^{1}$

A passagem destacada por Hilst provém da narrativa feita por Moran, um agente que toma a voz na segunda parte do livro de Beckett, ocupando-se do "caso Molloy", o qual confecciona um relatório. Da observação de Moran resulta que Molloy "rolava a cabeça, proferindo palavras ininteligíveis" e que "estava sempre a caminho". ${ }^{3}$ Não sem motivo, Moran fica muito perplexo. O que significa falar consigo mesmo? Como bem nota Paul Ricœur, colocar-se essa pergunta leva à reflexão acerca do "destino da subjetividade na literatura", 4 intimamente ligado à forma do monólogo interior. O monólogo

1 HILST, Hilda. Fluxo-floema. São Paulo: Globo, 2003, p. 5.

2 Beckett, Samuel. Molloy. Tradução de A. H. Souza. São Paulo: Globo, 2014, p. 149.

3 Idem, p. 158.

4 RICceur, Paul. Tempo e narrativa 2. A configuração do tempo na narrativa de ficção. Tradução de M. V. Martinez de Aguiar. São Paulo: Martins Fontes, 2010, p. 156. 
interior - confuso, plural e incessante - é a princípio "sem ouvinte e não pronunciado", a não ser em obras literárias daqueles autores que empreendem a vertiginosa tarefa de encenar a emergência - simultânea e incontrolável - da palavra, da emoção e do pensamento: Woolf, Proust (sobre quem Beckett escreveu um ensaio), Beckett, Hilst, entre outros. De fato, aquele monólogo ao qual se entrega Molloy, constituindo-se com isso para Moran em um indecifrável enigma, é acessível ao leitor na primeira parte do livro. Nada há então de estranho no fato de que um de seus temas recorrentes seja a própria linguagem.

Uma vez que a atividade linguística é também uma das questões mais perturbadoras de Fluxo-floema, a pesquisa dos traços da leitura da obra de Beckett feita por Hilst torna-se irresistível. Em uma entrevista de 1981, a autora descreve a excitação intelectual proporcionada por textos beckettianos, associando-a, entre outros, ao humor escatológico perante situações terríveis:

O Beckett me interessou muito, porque aí eu já senti ele como um desaforo, sabe, ele é um desaforo, tudo o que ele diz, entende? Então, o personagem conta todos os peidos que dá, e ele conta isso com uma mise-en-scène, com uma certa soberba e tal, e eu acho isso muito bom, sempre que você começa a falar de coisas que as pessoas têm medo. ${ }^{6}$

Hilst sublinha seu fascínio pelo irlandês, em quem descobre também a estranha eficácia dos gestos desesperados: "e esse homem me interessou, eu me interessei por toda a obra dele, e é o homem que eu mais admiro como escritor. Porque ele teve a coragem de assumir a própria condição e falar dessa condição grotesca, torpe quase, que é a condição humana". À primeira vista, Hilst aprende com Beckett sobretudo a arte do desaforo. Mas seriam os textos do irlandês realmente tão chocantes por sua abordagem do corpo em suas atividades escatológicas? Não se deve esquecer que, em 1981, quando descreve os motivos de sua admiração por Beckett, Hilda Hilst está no momento da construção

\footnotetext{
5 Sallenave, Danièle. "Em torno do 'monólogo interior': leitura de uma teoria”. In: Masculino, feminino, neutro. Ensaios de semiótica narrativa. Tradução de T. Franco Carvalhal et al. Porto Alegre: Editora Globo, 1976, p. 112.

6 DINIZ, Cristiano (org.). Fico besta quando me entendem. Entrevistas com Hilda Hilst. São Paulo: Globo, 2013, p. 8 o.

7 Ibidem.
} 
de sua persona artística, a da irreverente e escandalosa, trabalhando para se afirmar no mundo cultural brasileiro como "pornográfica, amaldiçoada, provocadora e obscena". Trata-se de uma tarefa difícil, ousada, que toca aos envolvimentos do feminino no simbólico, sem falar das questões editoriais, ou seja, as do mercado. Assim, jogando com uma das imagens estereotipadas do feminino - a da bruxa -, a escritora aposta na provocação, lançando mão de uma linguagem cada vez mais chula e da temática aparentemente pornográfica.

Em seus textos literários, em suas crônicas e nas entrevistas concedidas ao longo dos anos, Hilst procura então falar daquilo de que as pessoas têm medo; ou seja, pratica uma dicção poética e uma postura artística que colocam em questão a relação entre a arte e o pacto civilizatório. Mas não se deve esquecer que um de seus pornógrafos preferidos era Wittgenstein, alguém que se perguntava, por exemplo: “A palavra cujo significado não está claro é 'pura', ou 'saturada'. Como nós aprendemos esse significado? Como se sabe que os homens visam com ela ao mesmo?". ${ }^{9}$ Ele chegava até a afirmar: "Aquilo, acerca do que escrevo tão morosamente, pode ser óbvio para outrem com um entendimento são", ${ }^{10} \mathrm{ou}$ : "Aparece-me à noite um fantasma. Ele poderia então brilhar com um débil clarão claro; vejo-o porém cinza, então a luz precisaria provir de um outro lugar qualquer". ${ }^{11}$ Como Hilst mesma diz, o problema de verdade é que todos os seus personagens "têm o mau hábito de pensar". ${ }^{2}$ Com efeito, os personagens hilstianos pensam em demasia, exatamente como os de Beckett. E, de fato, especificando melhor os motivos de sua admiração pela obra beckettiana, a autora confirma: "Ele quer ir até o fim daquela questão, então ele contorna aquela questão de várias maneiras". ${ }^{13}$

"Contornar de várias maneiras" é o movimento que se dirige em Beckett tanto às questões existenciais quanto às atividades linguísticas, mostrando, inclusive, que os dois domínios estão visceralmente ligados. Bem o sabem os personagens beckettianos:

8 NAscimento, Elma Lia. “Farewell to a cursed poet”. Brazzil News 24/7. Brazzil Magazine, fev. 2004. Disponível em: http://www.brazzil.com/2004/html/articles/febo4/p1o6febo4.htm. Acesso em: 29 out. 2016. 9 Wittgenstein, Ludwig. Anotações sobre as cores. Tradução de J. C. Salles Pires da Silva. Campinas: Editora da Unicamp, 2009, p. 67.

10 Idem, p. 183.

11 Idem, p. 161.

12 DINIZ, Cristiano (org.). Fico besta quando me entendem, cit., p. 160.

13 Idem, p. 81. 
"Pois tudo se liga, na longa loucura do corpo, sinto assim". ${ }^{14}$ As ruminações de Molloy possuem como seu meio e como seu tema as palavras, que deixam de servir à comunicação e passam a ser tratadas ora como objetos ora como partes do corpo: manuseadas, reviradas, transformadas em fonte de sensações. Enquanto texto, Molloy pratica um abuso constante das palavras, em todas as suas "funções".

A relação entre linguagem e pensamento é contestada por meio da encenação da heteroglossia, que faz deslizar a questão existencial em uma pergunta feita no bar, descambando na animalidade: "esse rumor que se levanta no nascimento ou até mesmo antes, a esse insaciável Como fazer? Como fazer?, ora baixo, um murmúrio, ora claro como o E para beber? de um maître, e com frequência se ampliando até chegar a um rugido". ${ }^{15} \mathrm{O}$ vínculo entre linguagem e memória, vital para a experiência da identidade e para a narrativa da própria vida, é extremamente frouxo: "E essa cidade, a única que me foi dado conhecer, procurei-lhe o nome, na minha memória, com a intenção, assim que o tivesse encontrado, de parar a dizer a um transeunte, enquanto tirava chapéu, Desculpe-me, senhor, x é aqui?”. ${ }^{16}$ As relações de representação são desacreditadas: "Sim, as palavras que ouvia, e ouvia muito bem, tendo o ouvido bastante apurado, eu as ouvia da primeira vez, e ainda mesmo na segunda, e com frequência na terceira, como sons puros"; 17 "E as palavras que eu mesmo pronunciava e que deviam quase sempre se ligar a um esforço de inteligência, muitas vezes me davam a impressão do zumbido de um inseto". ${ }^{18}$ As próprias implicaturas conversacionais ficam altamente suspeitas: "que você minta ou se cale". ${ }^{19}$ Mas é na ideia da continuidade entre linguagem e corpo que se revela o teor da violência do ser humano enquanto "usuário" da linguagem: "Estabelecia uma comunicação com ela batendo-lhe no crânio. Uma pancada significava sim, duas não, três não sei, quatro dinheiro, cinco adeus". ${ }^{20}$ Nas palavras e até mesmo nas letras que as compõem insufla-se um sopro de vida monstruoso acompanhado de um niilismo linguístico: "E se

\footnotetext{
14 BECKetT, Samuel. Molloy, cit., p. 85.

15 Idem, p. 27.

16 Idem, p. 54.

17 Idem, p. 77.

18 Ibidem.

19 Idem, p. 125.

20 Idem, p. 36.
} 
a chamava de Mag era porque na minha cabeça, sem que soubesse dizer por quê, a letra $\mathrm{G}$ abolia a sílaba Ma, e por assim dizer cuspia em cima”. ${ }^{21}$

Estabelecer a comunicação batendo no crânio do outro grotescamente aponta para a interiorização do espaço interpessoal e, de fato, a cena da comunicação parece em Beckett engolida pela mente: "Eu fazia perguntas a mim mesmo por gosto, uma atrás da outra, só para contemplá-las. [...] Chamava isso de pensar". ${ }^{22}$ A cena da tradução, igualmente, abandona o espaço interlinguístico e é interiorizada pela subjetividade de Molloy: "esse problema que tinha em compreender não só o que os outros me diziam, mas também o que eu mesmo lhes dizia". ${ }^{23}$ Assim, a relação entre linguagem e pensamento expressa-se frequentemente em imagens do espaço sonoro interior, o do pensamento-escuta: "é um som que se põe a farfalhar na sua cabeça, não se sabe como, nem por quê. É com a cabeça que você o ouve, as orelhas não têm nada com isso"; ${ }^{24}$ "pus-me então a pensar, quer dizer, a escutar com mais força". ${ }^{25}$ Trata-se de uma espécie de palco interior cuja potencial obscenidade será plenamente apreendida por Elfriede Jelinek, que, ao dizer "Escuta é pensamento e de todo modo pode-se pensar tudo", ${ }^{26}$ aproxima o pensamento da pornografia.

Permeadas pela violência raramente encontrada na literatura, as atividades linguísticas tornam-se em Beckett essencialmente escatológicas:

E que eu diga isso ou aquilo ou outra coisa, na verdade pouco importa. Dizer é inventar. Falso como se espera. Você não inventa nada, acredita inventar, escapar, não faz mais que balbuciar sua lição, restos de um castigo, tarefa decorada e esquecida, a vida sem lágrimas, tal como você a chora. E depois que merda. Vejamos. ${ }^{27}$

Assim, o espaço interior beckettiano - violento e voraz à semelhança de uma incansável voragem - corresponde não apenas à cabeça, mas envolve o corpo inteiro: "todo esse

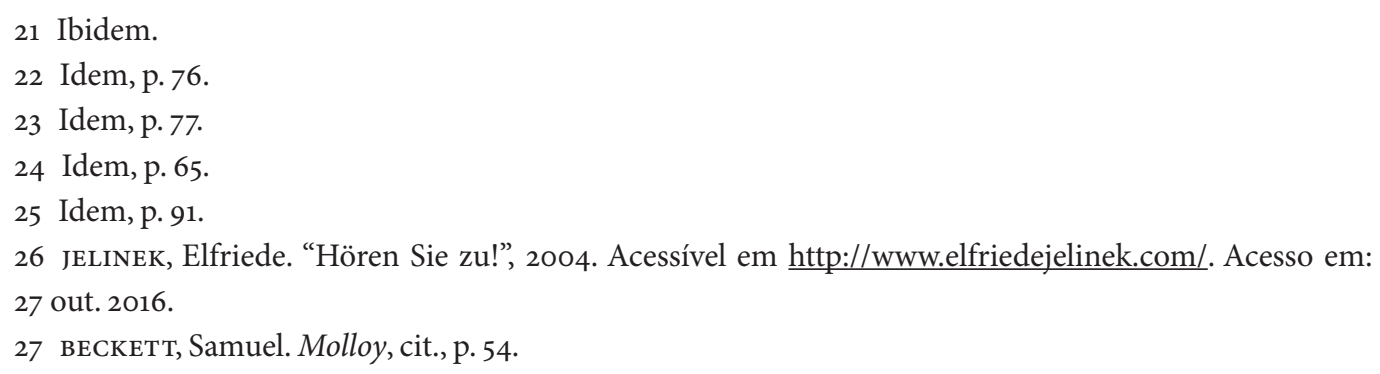


espaço interior que não se vê nunca, o cérebro e o coração e as outras cavernas onde o sentimento e o pensamento fazem seu sabá". ${ }^{28}$

A colocação da relação entre linguagem e corpo no contexto escatológico é, de fato, um dos traços mais marcantes da escrita hilstiana. O monólogo de Fluxo-floema propõe-se "escrever as coisas de dentro" ${ }^{29} \mathrm{e}, \mathrm{em}$ um movimento de cisão e inversão psicótica, o início da escrita se dá sob a forma do violentíssimo "Uc": "pega essa tua folha luminosa e escreve aí no meio da folha aquela palavra às avessas. Uc?". ${ }^{30}$ Abolida qualquer distância - condição de qualquer representação -, as operações linguísticas são comparadas aos distúrbios corporais: "A mesóclise é como uma cólica no meio do discurso: vem sempre". ${ }^{3}$

A cena da comunicação distribui-se no texto de Hilst entre as vozes que a toda hora invadem o palco interior da subjetividade: "Quero lhes contar do meu ser a três". ${ }^{32}$ O próprio movimento da invasão dá-se, aliás, em decorrência de associações linguísticas. A primeira delas liga os nomes próprios que, como em Beckett, começam com a mesma letra, prestando-se a confusões: "Ruiska" (o "eu" que fala na forma masculina), "Ruisis" (a interlocutora feminina) e "Rukah" (o interlocutor criança, filho morto). O interlocutor que assombra a subjetividade em crise é o "anão" que surge quando, após a morte do filho, Ruiska olha pelo telescópio uma anã branca. Grotesco e sublime, marcado pela dimensão cósmica, pela negação, mas também por associações excrementais, o "anão" ao mesmo tempo perturba e movimenta a cena da comunicação: "Donde você vem, hein? Do intestino, da cloaca do universo, do cone sombrio da lua". ${ }^{3}$ Surgem no texto considerações parafilosóficas que a toda hora lembram a irreverência do sentido, como, por exemplo, "existe em nós uma saída para tudo". ${ }^{34}$ Nesse palco intenso e aparentemente caótico, permeado pela multiplicidade de vozes, pela heteroglossia e pela coprologia, vêm sendo formuladas as questões caras à filosofia da linguagem, tais como, por exemplo, a pergunta pela relação entre o sentido e a linguagem privada - "Defino-

\footnotetext{
28 Idem, p. 27.

29 HILST, Hilda. Fluxo-floema, cit., p. 20.

30 Idem, p. 21.

31 Idem, p. 25.

32 Idem, p. 51.

33 Idem, p. 35 .

34 Idem, p. 29.
} 
te? Ou não te defino? Não é melhor que cada um defina o seu próprio anão?"35 -, a reflexão sobre os limites do dizível - "Há certas coisas que eu preferiria calar. Há outras que eu preferiria dizer. Agora não sei se digo as coisas que preferiria calar ou se calo as coisas que preferira dizer" ${ }^{36}$-, e até mesmo uma impressionante colocação em jogo de todos os sentidos da palavra "sentido", justamente "contornada" de várias maneiras: "Por favor, isso tudo tem sentido, tem sentido tudo o que aparentemente não tem sentido, e tem sentido tudo o que realmente não tem sentido. Ah, eu queria ter sentido. Eu queria ter sentido aquela água na cara outra vez $[\ldots]^{3}{ }^{37}$

Fluxo-floema, de 1970, é o primeiro livro de "prosa" de Hilda Hilst. Trata-se do momento-chave da mudança de sua dicção poética e da invenção daquela "prosa" irreverente, angustiada, intensa e muito difícil, enfim, hilstiana. De fato, aquilo que não transparece muito na fortuna crítica da obra de Hilst, atenta sobretudo à "sexualidade", é a tremenda sofisticação linguística de sua obra, inseparável de uma impressionante violência linguística. Essa complexidade é relatada abertamente, por exemplo, pelos tradutores da obra hilstiana como um grande desafio. Até mesmo em espanhol os empecilhos se revelam enormes, e Bárbara Belloc, uma das tradutoras argentinas de Hilst, insistiu repetidas vezes - inclusive no "Diálogo entre tradutores" ${ }^{38}$ organizado na UFF por Johannes Kretschmer - na grande dificuldade de tradução das supostas obscenidades, relacionando-as à riqueza do vocabulário, e, igualmente, aos jogos poéticos, sonoros e rítmicos.

Como então nasce essa escrita hilstiana? E qual é a importância da leitura de livros de Beckett para sua emergência? Conforme sublinha Alcir Pécora, Fluxo-floema surge em 1970, após uma "intensa e concentrada produção para teatro". ${ }^{39}$ Tanto Beckett quanto Hilst praticaram em seu fazer poético diferentes gêneros literários, e para ambos a forma dramática, explicitamente dialógica, teve uma importância capital. Nesse sentido, é significativo que as "narrativas" de ambos sejam frequentemente adaptadas ao

\footnotetext{
35 Idem, p. 38.

36 Ibidem.

37 Ibidem.

38 fundação biblioteca nacional. Romances de Hilda Hilst serão publicados na Argentina (s/a). Programa de Apoio à Tradução. Disponível em: https://bookcenterbrazil.wordpress.com/2012/10/26/romances-de-hilda-hilst-serao-publicados-na-argentina/. Acesso em: 3 nov. 2016.

39 HILst, Hilda. Fluxo-floema, cit., p. 9.
} 
teatro e encenadas como monólogos dramáticos. ${ }^{40} \mathrm{E}$ aquele movimento que, em Woolf e em Proust, era ainda "o vaguear e o jogar da consciência" ${ }^{41}$ adquire em Beckett e em Hilst traços mais abertamente dramáticos.

O interessante é que a brasileira tenha ficado fascinada não apenas pelo teatro beckettiano, mas também e, quem sabe, mais justamente por aquelas "narrativas" nas quais se dão o despojamento da representação e a interiorização do espaço da comunicação. O marco simbólico da epígrafe é nesse sentido eloquente: Molloy (o primeiro da trilogia beckettiana) foi importante na invenção da "prosa" hilstiana. A autora explicita alguns dos motivos da sua passagem para a prosa em primeira pessoa e, assim, em 1978, afirma sua predileção pelo uso do "eu", que a torna inseparável do desejo de "ter emoções com lucidez" ${ }^{42}$ Em 1989, Hilda Hilst torna mais explícita a relação entre o desejo de representar a intensidade subjetiva e o uso da primeira pessoa: "Não gosto muito da terceira pessoa por isso. Porque dá sempre uma aparência de artificialidade. $\mathrm{Na}$ primeira, posso me encarnar como cada um de nós, como os assassinos ou os santos". 43 $\mathrm{Na}$ entrevista de 1986, a autora comenta sua passagem da poesia para a "ficção", relacionando-a à urgência de expressar estados extremos, que, de fato, precisam ser ordenados para serem representados: "Através da poesia, não dava mais. Não cabia na poesia essa vontade de me ordenar. Aí aconteceu essa emergência toda de ficção". ${ }^{44}$ Como é surpreendente até hoje, apesar de tantos precedentes, dentre os quais Baudelaire, que também sentiu a necessidade de uma prosa "flexível e contrastante o suficiente para se adaptar aos movimentos líricos da alma", ${ }^{5}$ uma poeta dizer que a forma do poema era por demais estreita para a intensidade experimentada pela subjetividade! Essa preferência pela "ficção" em primeira pessoa corresponde então na obra hilstiana à vontade de se "fazer uma radiografia da emoção" ${ }^{6}$ e pode ser compreendida como um laboratório.

\footnotetext{
40 Para citarmos apenas encenações brasileiras recentes: em 2012, Matamoros (com Maíra Gerstner) e Primeiro amor (com Ana Kfouri).

41 AUERBACH, Erich. Mimesis. A representação da realidade na literatura ocidental. Vários tradutores (s/n). São Paulo: Perspectiva, 2004, p. 483.

42 DINIZ, Cristiano (org.). Fico besta quando me entendem, cit., p. 53.

43 Idem, p. 106.

44 Idem, p. 97.

45 Baudelaire, Charles. O spleen de Paris. Pequenos poemas em prosa. Tradução de A. Zir. Porto Alegre: L\&PM Pocket, 2016, p. 14.

46 DINIz, Cristiano (org.). Fico besta quando me entendem, cit., p. 125.
} 
Investida de características do lírico, do narrativo e do dramático, a ficção hilstiana torna-se um palco explosivo, dilacerante e extremamente doloroso da palavra-pensamento-emoção. Em 1993, a autora acrescenta ainda: "sempre quis falar do que não se pode falar, das emoções que são proibidas, porque vastas demais".47

Acompanhado de hibridismo genérico, o uso da primeira pessoa tem também consequências para a recepção. De fato, na leitura de um texto em primeira pessoa o leitor acaba por colocar em cena também sua "subjetividade". Quem sugeriu que o uso da primeira pessoa podia ser comparado ao efeito de um palco do "eu" foi Wolfgang Iser. Ao assinalar que o texto exerce uma influência sobre a posição do leitor, provocando-o a assumir um ponto de vista, ou seja, um papel, a teoria iseriana deixa entrever que, ao ler um texto, o leitor "pensa os pensamentos de um outro". ${ }^{8}$ Assim, na leitura de um texto em primeira pessoa, o leitor arrisca-se em pronunciar um "eu". Ainda que saiba que o "eu" assim pronunciado não é seu, a experiência de pronunciar mentalmente o pronome pode levar a uma espécie de suspensão potencial da divisão entre sujeito e alteridade.

Iniciando-se como submisso à sintaxe e dividido em frases, e transformando-se em um fluxo contínuo sem pontuação, o ritmo do primeiro texto de Fluxo-floema traz reminiscências da articulação rítmica de $O$ inominável, que se inicia como separado em frases, evolui alongando os períodos, e termina em um amálgama discursivo "sem fim", sua última "frase" transbordando por mais de quatro páginas e chegando àquela fórmula que se tornou quase provérbio: "é preciso continuar, não posso continuar, vou continuar". ${ }^{49}$ No entanto, diferentemente de Beckett, que não investe de tanta materialidade as outras vozes, em Hilst o monólogo interior assume características mais abertamente dramáticas. Com isso, o texto hilstiano parece falar mais alto. Além de Ruiska que instaura o monólogo, Ruisis e o anão também têm sua voz e sua vez de falar. Assim, a presença explícita de outras vozes que a toda hora parecem se intrometer para perturbar a linearidade da fala provoca uma diferença rítmica muito significativa entre os dois textos: o de Beckett desdobra-se em um movimento monovocal que tende à regularidade, enquanto o de Hilst sofre múltiplas rupturas e acelerações resultantes das trocas de voz. O ritmo da narrativa hilstiana é brusco, vertiginoso e, como nota Vera Queiroz,

47 Idem, p. 149.

48 ISER, Wolfgang. O ato da leitura. Uma teoria do efeito estético. Vol. 2. Tradução de J. Kretschmer. São Paulo: Editora 34, 1999, p. 85.

49 Beckett, Samuel. O inominável. Tradução de A. H. Souza. São Paulo: Globo, 2009, p. 185. 
faz com que o leitor se veja "numa montanha russa, em alta velocidade".50 Se Beckett é despojamento e "exaustão", ${ }^{1}$ também no sentido rítmico, Hilst é excesso e agonia. Ela mesma torna explícita essa diferença capital: enquanto ele escreve que não pode dizer mais, ela prefere dizer: "Quero falar tudo nos meus textos e posso dizer ainda mais".52

Existem no texto hilstiano muitos "momentos" beckettianos relacionados ora a expressões ora a temas. Logo no início de Fluxo-floema, por exemplo, o próprio gesto de assumir a voz e de contar a história sobre o menino, o monstro e o crisântemo é beckettiano na medida em que corresponde a uma tentativa de se acalmar: "CALMA, CALMA, também tudo não é assim escuridão e morte. Calma. Não é assim? Uma vez um menino foi colher crisântemos [...]"..53 Esse início não seria uma réplica a Beckett? Nos textos do irlandês, aquele gesto antigo das Mil e uma noites, o de contar histórias para não morrer, torna-se desesperadamente reflexivo, e os narradores de Malone morre ou de O calmante contam-se histórias. Ou pelo menos tentam: "Logo enfim vou estar bem morto apesar de tudo. [...] Enquanto espero, vou tentar me contar histórias, se puder". 54 "Pois tenho medo demais esta noite para me escutar apodrecer [...]. Vou portanto me contar uma história, vou portanto tentar me contar uma história, para tentar me acalmar, [...]." ${ }^{55}$ Marcado - como tantos personagens beckettianos - pela relação tóxica com a mãe e por uma solidão atroz, o narrador de "Osmo" também tenta contar: "eu gostaria realmente de lhes contar a minha estória". ${ }^{6}$ Como no caso de Malone, surgem logo impedimentos: "não tenho a menor vontade de escrevê-la", ${ }^{57}$ e a narrativa é substituída por um fluxo discursivo em torno a uma palavra: "a minha mãezinha não me aguentava porque ela era louca para dançar, dançar isso mesmo, eu espero que vocês saibam o que é dançar". ${ }^{58}$

Tal como os personagens beckettianos entregues à dúvida acerca de seu nome esquecido, confundido, deformado ou multiplicado -, os de Hilst tampouco têm seu nome:

\footnotetext{
50 QUeIroz, Vera. Hilda Hilst: três leituras. Florianópolis: Editora Mulheres, 200o, p. 24.

51 Deleuze, Gilles. “The Exhausted”. In: Essays Critical and Clinical. London: Verso, 1998, pp. 152-74.

52 DINIz, Cristiano (org.). Fico besta quando me entendem, cit., p. 34.

53 HILst, Hilda. Fluxo-floema, cit., p. 19.

54 Beckett, Samuel. Malone morre. Tradução de P. Leminski. São Paulo: Brasiliense, 1986, pp. 5-6.

55 Idem, Novelas. Tradução de E. Araújo Ribeiro. São Paulo: Martins Fontes, 2006, p. 27.

56 HILst, Hilda. Fluxo-floema, cit., p. 75.

57 Idem, p. 76.

58 Ibidem.
} 
"eu me chamo Osmo, quero dizer, para vocês eu digo que me chamo Osmo, mas o meu nome verdadeiro, se é que a gente tem um nome verdadeiro, tem sim, mas o nome verdadeiro não interessa". ${ }^{59}$ Além disso, enquanto muitos dos personagens beckettianos têm dificuldades de andar, em Hilst a bengala é logo associada à forma verbal: "Peço a Ruisis minha bengala de jacarandá com aquela cara na ponta, e vou saindo. Gerúndio. Gerundivo”.60

“No entanto, sem que se possa - nem longinquamente - falar de influência, há uma afinidade espiritual enraizada com os textos flamejantes de Samuel Beckett." ${ }^{1}$ Diferentemente do que afirma Gilson Ribeiro, parece que existe sim influência de Beckett na obra ficcional de Hilda Hilst e que ela está em uma relação direta com as práticas linguísticas e poéticas, não se limitando ao gesto de pôr "em dúvida a existência de Deus". 62

Existem, é claro, muitas diferenças, dentre as quais a distribuição genérica das vozes, que em Beckett são predominantemente masculinas (com poucas exceções extremamente significativas, mas não em narrativas longas: Winne dos Dias felizes, "ela" de Mal visto mal dito). Se no primeiro livro de prosa de Hilst também se fala predominantemente no masculino (Matamoros há de esperar ainda alguns anos), isso talvez aponte tanto para a importância de Beckett para a formação da dicção hilstiana, quanto para a dificuldade da articulação discursiva no feminino de uma radiografia da emoção. A necessidade dessa diç̧ão deixa-se, contudo, fazer sentir desde o início: por mais que o discurso principal aconteça no masculino, ele logo se vê entremeado com o feminino, ora por meio de mistura - "eu menino, eu ancião, eu fêmea" ${ }^{3}$-, ora por meio de conflito, como em "Osmo", onde se disputam os usos e os abusos da palavra "dançar". Não há dúvida de que, do ponto de vista das relações de gênero, a conquista da dicção de Hilda Hilst tenha sido dificílima.

É preciso ressaltar também a diferença quanto ao perfil social dos personagens: em Beckett geralmente desempregados; em Hilst, frequentemente empresários, tal como

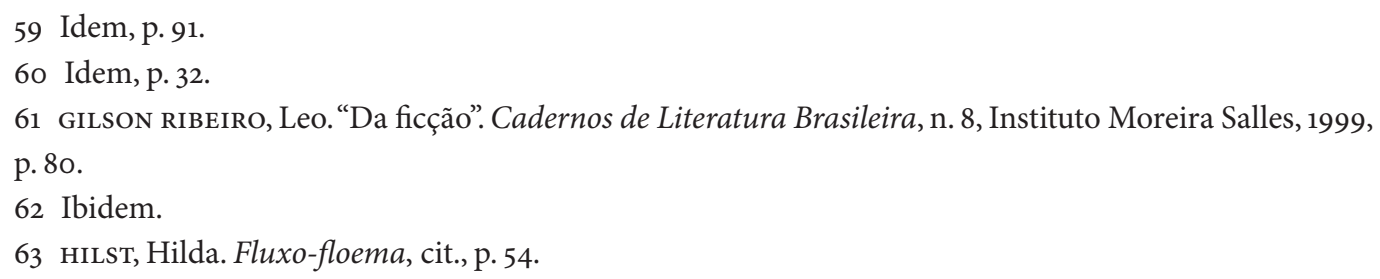


Osmo e depois Tadeu, ainda que no sentido muito kafkiano do "emprego". Mas a diferença mais significativa diz respeito à experiência da escrita em uma língua estrangeira e à prática do excesso de heteroglossia. Enquanto Beckett transita entre duas línguas, Hilst satura a língua própria, tornando-se nesse sentido mais próxima de Joyce (contra quem Beckett escrevia, optando pelo despojamento).

Hilda Hilst admitiu aquilo que era também verdade para Beckett e que ele provavelmente teria admitido: "Não escrevo porque eu, realmente, tenha que dizer muita coisa. Escrevo porque preciso me salvar". ${ }^{64}$ Mas a brasileira foi mais longe, ao dizer: "Estou convencida de que o amor é a única coisa a se viver". ${ }^{65} \mathrm{E}$ nos tempos nos quais até a arte, no intuito de se adaptar às sensibilidades do "sempre mais" moldadas pelo mercado, se fez toda estranhamento, novidade e provocação, a escandalosa bruxa Hilda Hilst colocou-se também essa pergunta, que mais uma vez contorna a "questão" de uma maneira inesperada:

É justamente o que eu queria discutir com você: eticamente algum escritor, alguma pessoa, pode assumir a tremenda responsabilidade de romper os limites que o outro aceitou, ou porque lhe foram impostos de fora ou porque se arrumou diante dessa conciliação com a opressão externa e o condicionamento interno de que foi vítima? Revelar ao outro que ele pode ser muito mais e pode ser ele mesmo com uma liberdade total de qualquer tipo de repressão política, econômica, sexual, religiosa, psicológica etc., eu me pergunto, não pode levar uma pessoa à morte, à loucura sem retorno?66

Olga Kempinska é Professora Adjunta da Universidade Federal Fluminense

64 DINIZ, Cristiano (org.). Fico besta quando me entendem, cit., p. 127.

65 Idem, p. 39.

66 Idem, p. 57. 